\title{
Using Building Information Modeling (BIM) for Estimating and Scheduling, Adoption Barriers
}

\author{
Juan Franco, Faiza Mahdi, Hussein Abaza* \\ Department of Construction Management, Kennesaw State University, USA
}

Copyright $(\mathcal{C} 2015$ by authors, all rights reserved. Authors agree that this article remains permanently open access under the terms of the Creative Commons Attribution License 4.0 International License

\begin{abstract}
Building information modeling (BIM) is changing how buildings, infrastructures, and utilities are planned, designed, built, and managed. Though very popular for collaboration and coordination in structural, mechanical, plumbing, and electrical trades in multi-family projects, this study shows that BIM is rarely used for estimating and scheduling due to the cost and time it takes to complete the BIM model. However, BIM is providing broad benefits and becoming an essential construction document component for large projects. The objective of this study is to identify the major barriers to using BIM for a project's estimating and scheduling. Personal interviews and electronic questionnaires for 30 companies were used to answer the research objectives. The study focused on how sub-contractors are currently using BIM for estimating and scheduling. The study provides recommendations on using BIM for estimating. In addition, the paper presents a case study for using light gauge metal framing add on to BIM software for estimating and shop drawing, thereby incentivizing contractors to challenge the existing barriers to use BIM more efficiently. The research showed that less than $7 \%$ of multi-family contractors use BIM in their projects and less than $3 \%$ use it for estimating. The case study showed that using BIM for framing and drywall estimating in multi-family residential construction or similar projects can be practical if a basic BIM model is provided to subcontractors.
\end{abstract}

Keywords BIM, Estimating, Light Gauge Metal Framing, Sub-contractors

\section{Introduction}

The United States' National Institute of Building Sciences (NIBS) defines BIM as "a digital representation of physical and functional characteristics of a facility. As such it serves as a shared knowledge resource for information about a facility forming a reliable basis for decisions during its life-cycle from inception onward" (2007, p. 21).

$\mathrm{BIM}$ is considered to be the auspicious new developments in the architecture, engineering, and construction (AEC) industry. It is a potential standard for AEC, by bringing together all the involved stakeholders of a project (Azhar, 2011).

A comprehensive BIM can provide most information needed for the construction of a building and throughout its life if updated as needed and made available for owners, developers, engineers, architects, contractors and facility mangers. Parties can input information and exchange it with others in 3D representations (National Institute of Building Sciences, 2015). BIM is underlying the need to move from the conventional approach of project participants working on separate information pools typically with different and incompatible software technologies to a unified common platform whereby all members can exchange the same information. (Smith, 2014). BIM is a process that constitutes a fusion of two and three dimensional design, scheduling and cost estimating in one single model (Deutsch, 2011).

Currently, the prime use of BIM is collaboration and coordination, clash detection, and work sequencing in structural, mechanical, plumbing, and electrical trades. BIM can also be expanded from a typical 3D building representation to a fourth dimension (time) referred to as 4D design, which can reduce conflicts in the project process. Furthermore, a fifth dimension (cost) referred to as 5D design can be added. The addition of 4D and 5D will eventually reduce time and errors that may occur in the conventional way of scheduling and estimating the project. (Kraus, Watt, \& Larson, 2007).

BIM enables participants to easily predict the performance of projects during preconstruction, construction and Post Occupancy evaluation as well as building maintenance. BIM also allows for faster changes with high quality construction documentations delivery (Smith, 2014). Furthermore, BIM increases the accuracy in the quantity takeoff especially at the early stage of the design and allow precise future prediction of the construction costs. (Choi, H. Kim \& I. Kim, 2014). BIM is established by the combination of multi-dimensional objects which provide detailed information about their role in the model (Azhar \& Brown, 2009). This facilitates the process of the automated estimating of the project (Deutsch, 2011). In addition to the 
schedule creation based on the existing information on BIM (Woo, 2007), thus, any added updates will be reflected on the entire parts of project due to the interrelated (Sylvester \& Dietrich, 2010).

BIM is gaining rapid popularity in the architecture, engineering, and construction (AEC) industry fields. (Sattineni, 2011). A case study by Brittany, Giell and Raja (2013) supports the return on investment by the implementation of BIM. Results of the research demonstrated considerable reduction of change orders, requests for information, and project completion within the project schedule. Though, the initial cost of BIM is hampering industry professionals of using it as a mainstream in every project. (Giel \& Issa, 2013). Another study by Azhar (2011) confirmed the return on investment of BIM implementation by an average of $634 \%$ based on case studies in the following projects: Aquarium Hilton Garden Inn, Atlanta, GA- Savannah State University, Savannah, GAThe Mansion on Peachtree, Atlanta, GA- Emory Psychology Building, Atlanta, GA. This illustrates its prospective economic benefit. As a result, a lot of questions about the investment of BIM in cost estimating are still not answered.

This study identifies the major barriers for BIM adaption in cost estimating. The study also details the benefits of using BIM for cost estimating for subcontractors to adopt BIM. As a case study, we examined the efficiency of using BIM for estimating light gauge metal framing in multi-family housing projects. First, an estimation of the metal framing and drywall of a multi-family housing project was performed using On Screen Takeoff estimating software. Second, a BIM model was built from CAD files and then used to estimate the same line items. The BIM model was also used to generate shop drawings for the project. This research highlighted the barriers in using BIM in estimating and provided basic guidelines for general contractors and framing subcontractors on the areas were BIM can be used efficiently in estimating and generating shop drawings.

\section{Background}

Research by McCuen, (2008) affirmed the broad benefits of involving scheduling (4D) and cost estimating (5D) in the project which gives spirit to BIM, "Adding $4 \mathrm{D}$ and 5D to a BIM project creates an environment that enhances profitability". A case study by McCuen, (2008) demonstrated the scheduling and estimating involvement that resulted in the success of the project "University of Washington (UW) Research Building" by its completion $40 \%$ faster than the projected time. BIM facilitated the collaboration between the different stakeholders, and exceeded the owner's quality expectations of the project. Mortenson, (2007) claimed that, "The model has proven comprehensive and durable enough to assist in all phases of the project lifecycle-from conception, through design and construction, to operations and maintenance."

The benefits and outcome of BIM implementation can be utilized to justify the need to promote BIM in the architecture, engineering and construction industry. (Lu, Fung, Peng, Liang \& Rowlinson, 2014). Edward (2007) claimed "One of the major benefits of BIM is that it includes information about length, width, and volume, as well as information about content such as doors, windows, and finishes, all of which can be used for estimation." Moreover, estimating based on BIM eliminates overlooked details when doing quantity takeoff from traditional 2D mostly with common updates which makes it hard to catch. (Joyce \& Erin, 2014).

Nassar conducted research related to BIM application in estimating. The research based on data collected from students working on project with BIM/Estimating, a course offered for graduate students, results from the actual projects were used and analyzed as follow: The application of BIM for estimating purposes can dramatically improve time savings and quantities' accuracy at any time during the construction process. Since the 3D model is based on updated documents by the side of the relevant data, yet, this process is still hindered by the lack of understanding (Nassar, 2012). Moreover, the automated takeoff cannot be produced only by BIM. Findings by Stanley and Thurnell (2014) show that "5D BIM takes place outside the core BIM model by live linking it to a third party estimating software". Thus, an emphasis of introducing estimating software to link BIM and the model (Nassar, 2012). Nassar also supported the importance of creating a specific BIM model for contractor's benefit rather than working on the BIM model provided by architects and engineers, "The estimating process is more complex than merely listing objects and their sizes" (Nassar, 2012)

Research by Thurairajah and Goucher (2013) concluded that the implementation of BIM within the project changed the vision of the construction. Surveying professionals are being influenced by the expansion of BIM. Thus, it promotes its use and makes its presence necessary to the project success. Otherwise, they will chance the menace of falling behind the competition. It is crucial to understand the advantages and challenges of BIM; BIM's magnitude to impact the project in all aspects and phases. Moreover, the effective and accurate delivered information, estimates that cost consultants can rely on. Thurairajah and Goucher (2013) found that there is a likely time enhancement with the process of automation while meeting the owner's expectations and the project team's expectations. However, an absence of motivation of investment is noticed. Thurairajah and Goucher (2013) stated "It is essential that BIM is introduced to organizations as part of a structured implementation plan, with the required levels of sensitivity." The study also pointed out the deficiency of comprehension of BIM among cost consultants, and an essential need for training.

Stanley and Thurnell (2014) found that BIM estimating is more efficient, accurate, detailed, and predictive for eventual future problems in counter of a conventional quantity surveying. Nevertheless, BIM estimating is kept to adoption by the following obstacles: Cost, absence of software compatibility, absence of specific coding for BIM elements, 
deficiency of full information for data, absence of united models. McCuen (2009) clarified that extracted information from BIM are not necessarily efficient (National Institute of Building Sciences, 2007). "The information needs to be in the appropriate format and considered accurate and complete before use in decision making" McCuen (2009). This will occur by transferring data linking multiple dimensions using software that is interoperable (National BIM Standard, 2008).

Literature covered the subject of BIM mainly for collaboration and coordination counter to the use of BIM for estimating, which is still considered an innovation. Large construction companies started to realize the importance of BIM model especially in design-build projects and implement them in the design phase and in during the construction for scheduling and clash detection, other construction companies especially building subcontractors did not see the incentive of developing a BIM model for their own use especially when it is not given to them by the architect of the Construction company. Since most papers favor large-scale projects, this study explored multi-family projects. Broad questions were framed from the literature review due to the lack of research in this topic. This paper attempted to add rigor to the existing research by addressing the subcontractors' challenges to adopt BIM for estimating with a framing design BIM module.

\section{Research Methodology}

In this study, we use a triangulated approach which involved both qualitative and quantitative methods for a multi-dimensional view of the subject. The research methodology involves survey of construction and architecture company, interview with contractors and a case study of using BIM for estimating and shop drawings.

\section{Survey}

The primary survey data was collected through interviews with multi-family projects' contractors in Atlanta, GA. The interviews were carried out during March and April, 2015. A survey was also distributed through personal e-mails to project managers who have the authority to influence the decision-makers related to using BIM for cost estimating.

The questionnaire was sent to 137 people in different companies through personal e-mails. 11 returned as undeliverable, 32 responded. The survey consists of the following questions:

1. At what percentage do you use BIM software (Revit, ArchiCAD, etc.) in your projects?

2. Do you use BIM software for estimating?

a. If not, do you plan on using BIM in the future for estimating?

b. If yes, do you build the model yourself or get it from the architect?

3. Do you use BIM software for scheduling?

a. If not, do you plan on using BIM in the future for scheduling?

b. If yes, do you build the model yourself or get it from the architect?

4. Architect if available, if not build it in house

5. During the estimating process do you require BIM models from subcontractors? If so, from which trades?

\section{Case Study}

As part of the study, a graduate student with moderate Revit skills and four years' experience working as a drywall and metal framing estimator, compared the accuracy and efficiency of traditional method of estimating using On Screen Takeoff and BIM Light Gauge Framing Software. On Screen Takeoff software is one of the most widely used software in the construction industry. It allows contractors to calculate building components and assemblies from PDF files, highlite them, and tabulate them and export them to electronic spreadsheets. The scope of this exercise was limited to estimating the light gauge metal wall framing and the drywall. A BIM model was built using Revit with third party Add-on for the light gauge metal framing. The student used a manual supplied online to learn and use the software over a two week period. (Figure 1). Although he students who built the model did not have previous experience in Revit, they posses knowledge in other drafting software, and they were advised by their peer when needed. Professional who might not have any experience with drafting software might take more time to develop the model.

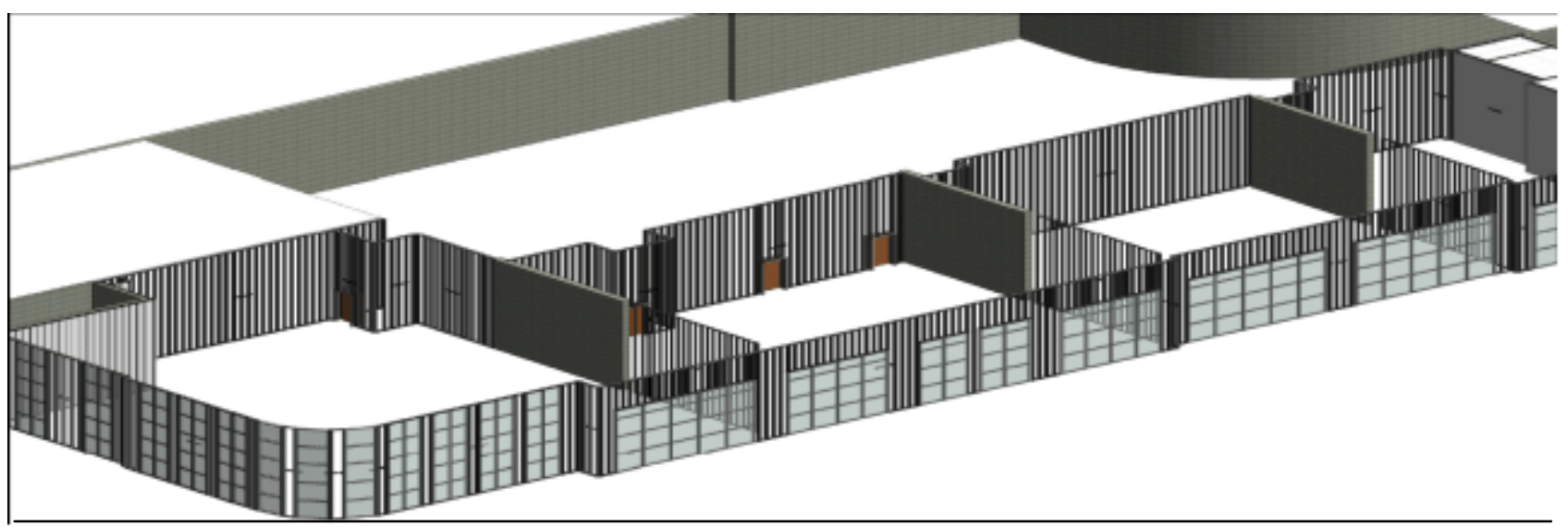

Figure 1. BIM light gauge metal framing $3 \mathrm{D}$ view 


\section{Results}

On Screen takeoff was used to find the total amount of drywall. (Figure 2). An estimate performed using On Screen Takeoff resulted in 67,152 sf of drywall or $13994 \times 12$ sheets. An estimate using schedules created in REVIT for exterior drywall and interior drywall resulted in $68,496 \mathrm{sf}$ or $14274 \times 12$ sheets. A difference of 1344 sf or $284 \times 12$ sheets. This represents a difference of about $2 \%$. The difference in drywall can best be attributed to openings not accounted for in the On Screen Takeoff estimate such as small doors and windows. Overall the material estimate was accurate.

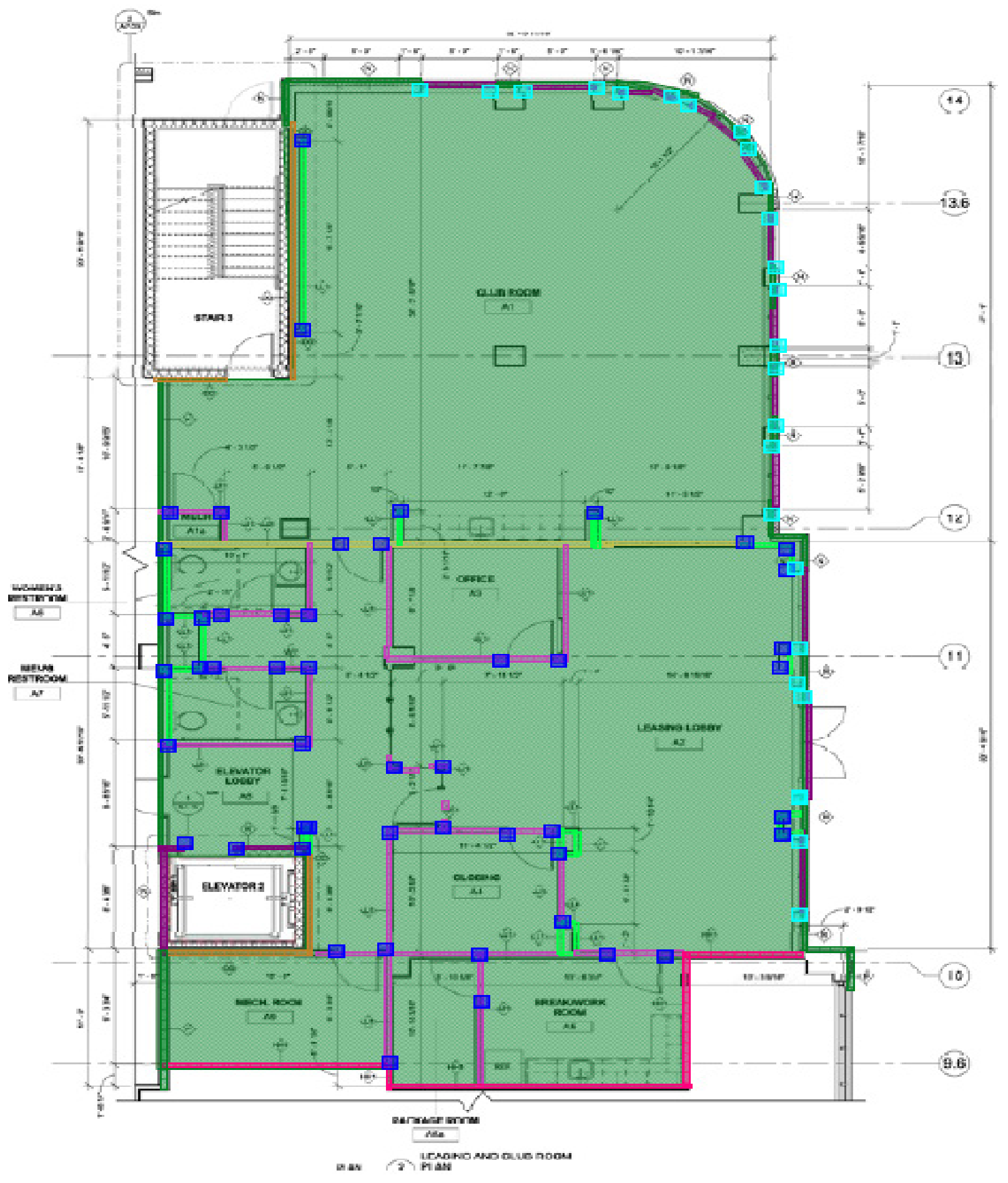

Figure 2. On Screen Takeoff 
The case study showed that the use of a BIM framing design module was more accurate in determining the sizes and gauges of the metal framing and provided the benefit of generating shop drawings. The primary reason for the accuracy of the BIM framing design module is its ability to automatically calculate the framing required once a lineal deflection is inputted. The ability to visualize the framing in $3 \mathrm{D}$ and the tagged positioning of the wall panels and members further assured greater accuracy than On Screen Takeoff

The student's very limited training and experience using a BIM framing design module limited the scope of work that was included in the metal framing. The box headers that would be typically incorporated into opening spans were not included as the student had difficulty inserting them into the framing. The boxed headers inserted in On Screen Takeoff were removed to allow for accurate comparison among the two estimating methods. The difficulty inserting the boxed headers is not a reflection on the ability of a BIM framing design module to perform the task, but merely the lack of suitable training of the student and perhaps the deficient instruction provided in the training manual.
The project used in the study is a mixed use development in Sandy Springs, GA with light gauge metal framing of the retail space and two units with the remainder of the structure wood framed. (Figure 3). The material pricing was obtained from local suppliers used in the actual construction of the project. The BIM framing design module estimate equaled $\$ 30,326.72$ and the On Screen Takeoff equaled \$26,032.76. The difference between the two estimating methods was $\$ 4,293.96$ or about $15 \%$.

An analysis of the difference in price reveals that the inputting of the lateral deflection in the BIM framing design module changed the on center spacing of the interior 20 foot high walls from 16" O.C. to 12" O.C. 20 gauge and also changed the gauge of the exterior framing from solely 18 gauge to 18 gauge and 14 gauge depending on the height. The 10 ' high walls were 18 gauge and the 20 ' walls were 14 gauge. These changes accounted for the difference in the estimated material costs. The student, when providing the estimate using On Screen Takeoff, stipulated that the bid provided for 18 gauge exterior walls only and if shop drawings required a heavier gauge, an adjustment to the price would follow. (Figure 4.)

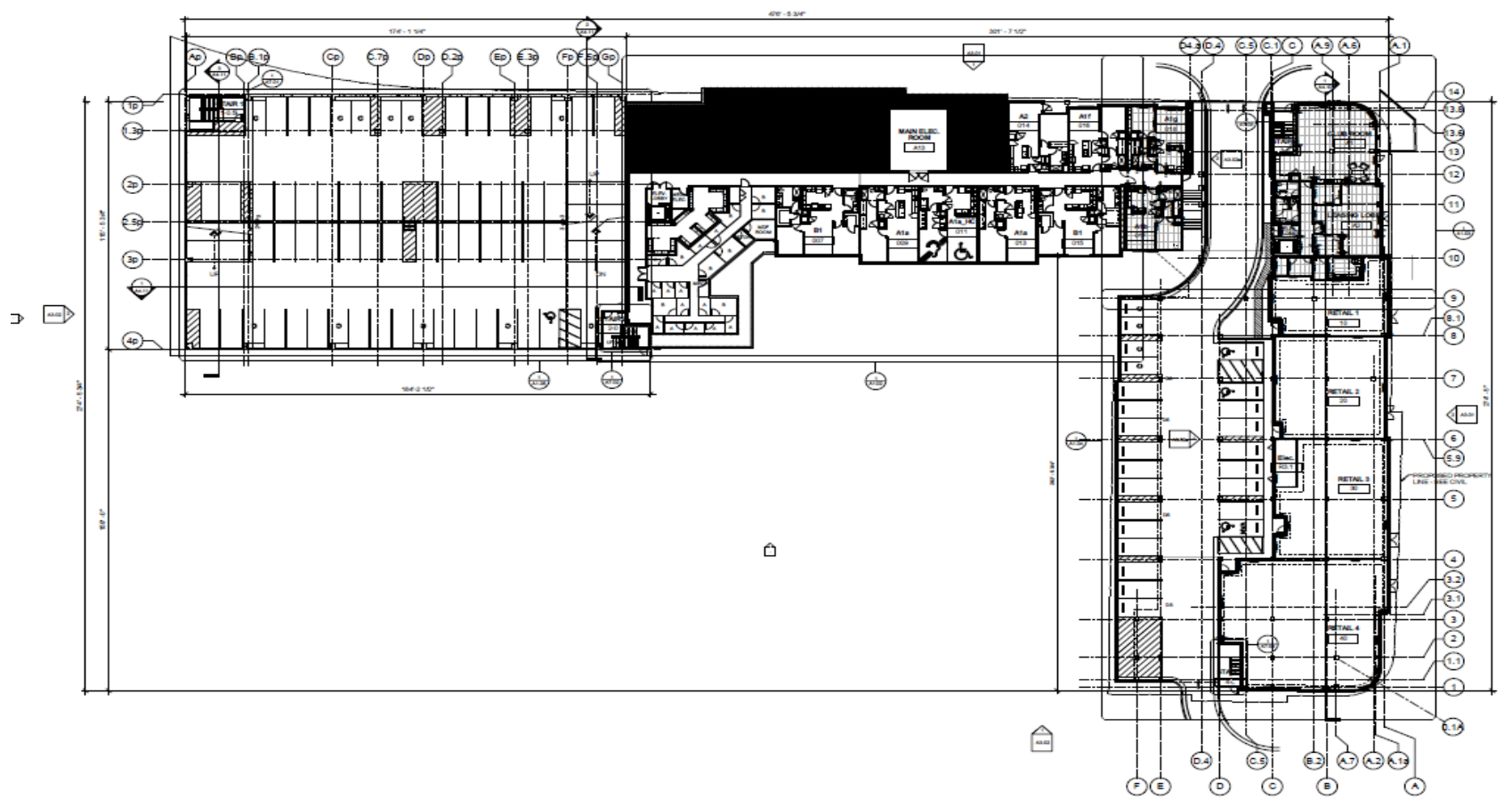

Figure 3. Multi Family project Floor Plan 


\begin{tabular}{|c|c|c|}
\hline Lbl Qty & Member & $W(\mathrm{lbs})$ \\
\hline $\mathrm{CO}$ & 600S162-43(33)10' & 106.4 \\
\hline C1 & 600S162-43(33)2' $0 "$ & 18.24 \\
\hline C2 & 600S162-43(33)8' 0" & 24.32 \\
\hline TO & 600CST250-33 12' 0" & 0.0157 \\
\hline T1 & 600T125-43(33)2'" 0" & 2.6 \\
\hline T2 & 600T125-43(33)4' 0" & 5.2 \\
\hline T3 & 600T125-33 & 0.0066 \\
\hline - & Grand Total: & 156.7823 \\
\hline
\end{tabular}

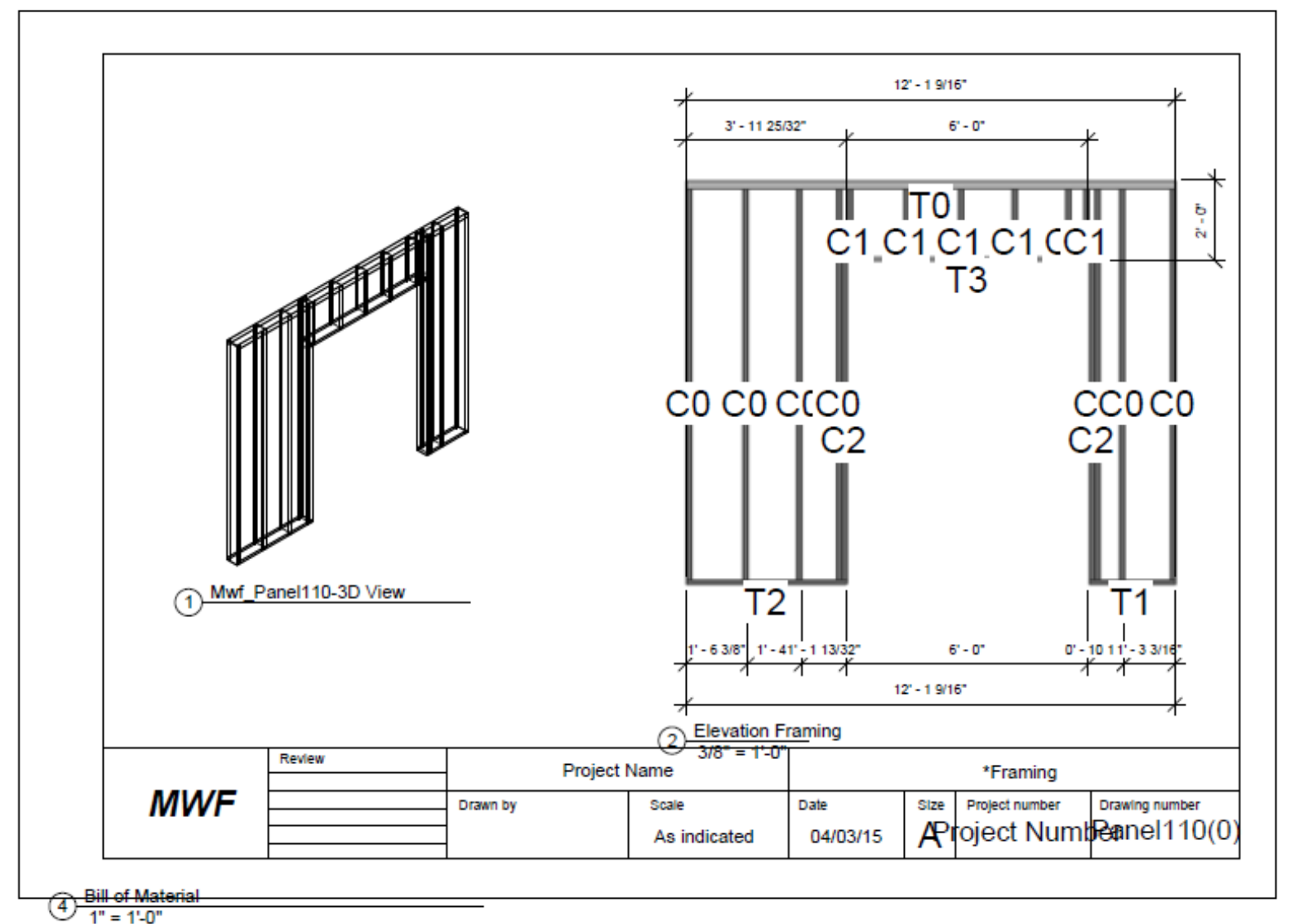

Figure 4. Shop Drawing with Material List

Since the student was able to input the lateral deflection, a more accurate estimate could be provided to the owner from the beginning of the project. The size, gauge and on center spacing required to meet the lateral deflection proved to be a great benefit. The estimator could more accurately provide the owner with material costs and the contractor with proper stocking when ordering the materials.

A major caveat to the study as regards the efficiency of the software is the source of the REVIT model. If the REVIT model is provided by the Architect to the estimator, the estimator's time spent building the model would be deducted from the overall time to complete the takeoff. (The On Screen Takeoff estimating method is much faster than building a REVIT model and then building the metal framing model using the BIM framing module. The student performed the on screen takeoff in two hours. The student was provided the AUTOCAD model from the architect and then built the REVIT model from this set in 11 hours. The modeling using the BIM framing module added 4 hours. Again, the student's lack of training and first time use of the BIM framing module software must be taken into consideration. However, a good deal of information must be inputted into the BIM framing module in order to obtain accurate framing.

The primary negative of using a BIM framing module and REVIT as a whole in estimating is the time spent building the actual REVIT model. If the estimator has to build his/her own model, then the time spent building the model would make the use of REVIT and the BIM framing module inefficient. If, however, an architect provided the REVIT 
model to the estimator, then it appears that once properly trained the use of the BIM framing module would be efficient. The efficiency and accuracy gained in providing the proper lateral deflection requirements plus the ability to generate shop drawings would make the software a greatly valuable estimating tool.

\section{Survey Results}

Data analysis and observations driven from interviews and the survey questionnaire was explained in form of the following charts:

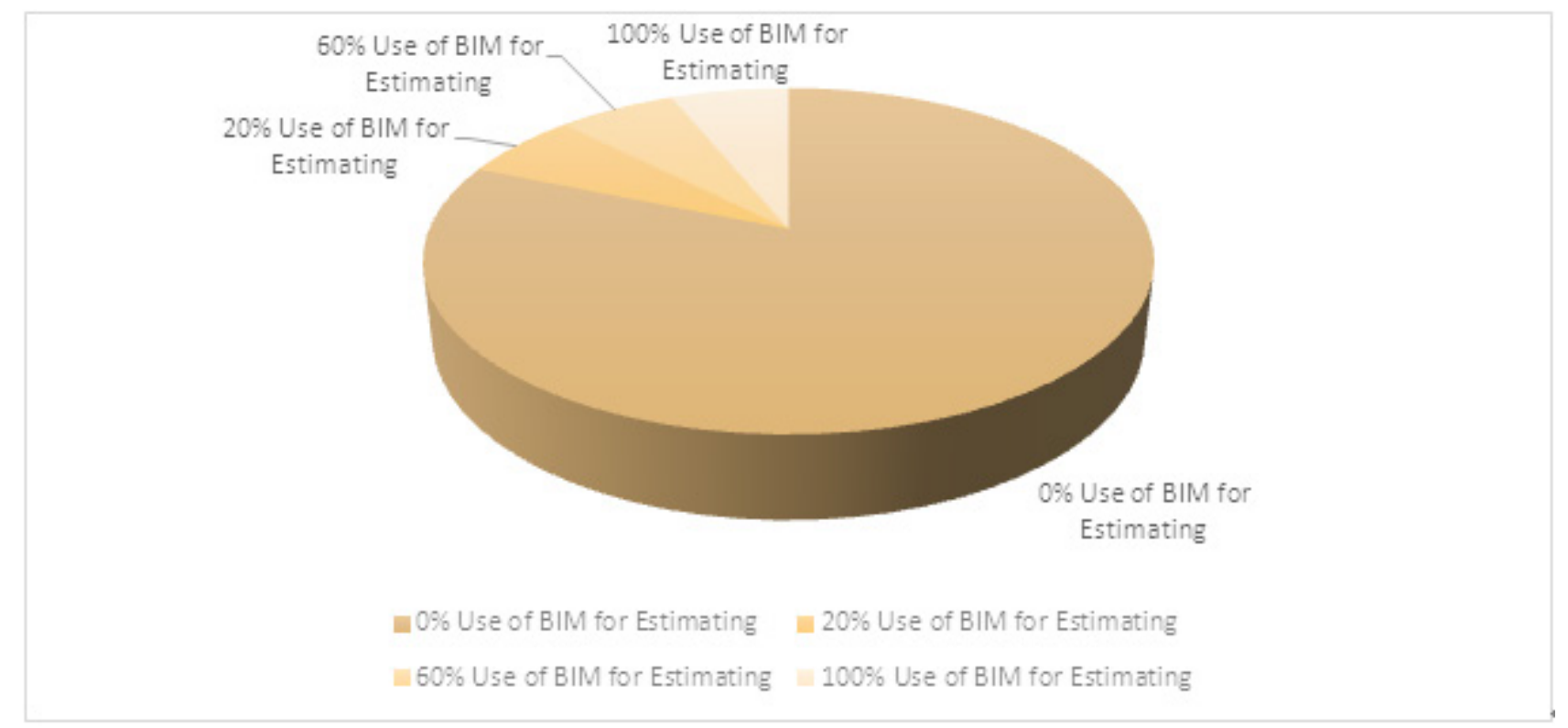

Chart 1. Percentage of BIM use (Revit, ArchiCAD) in Projects

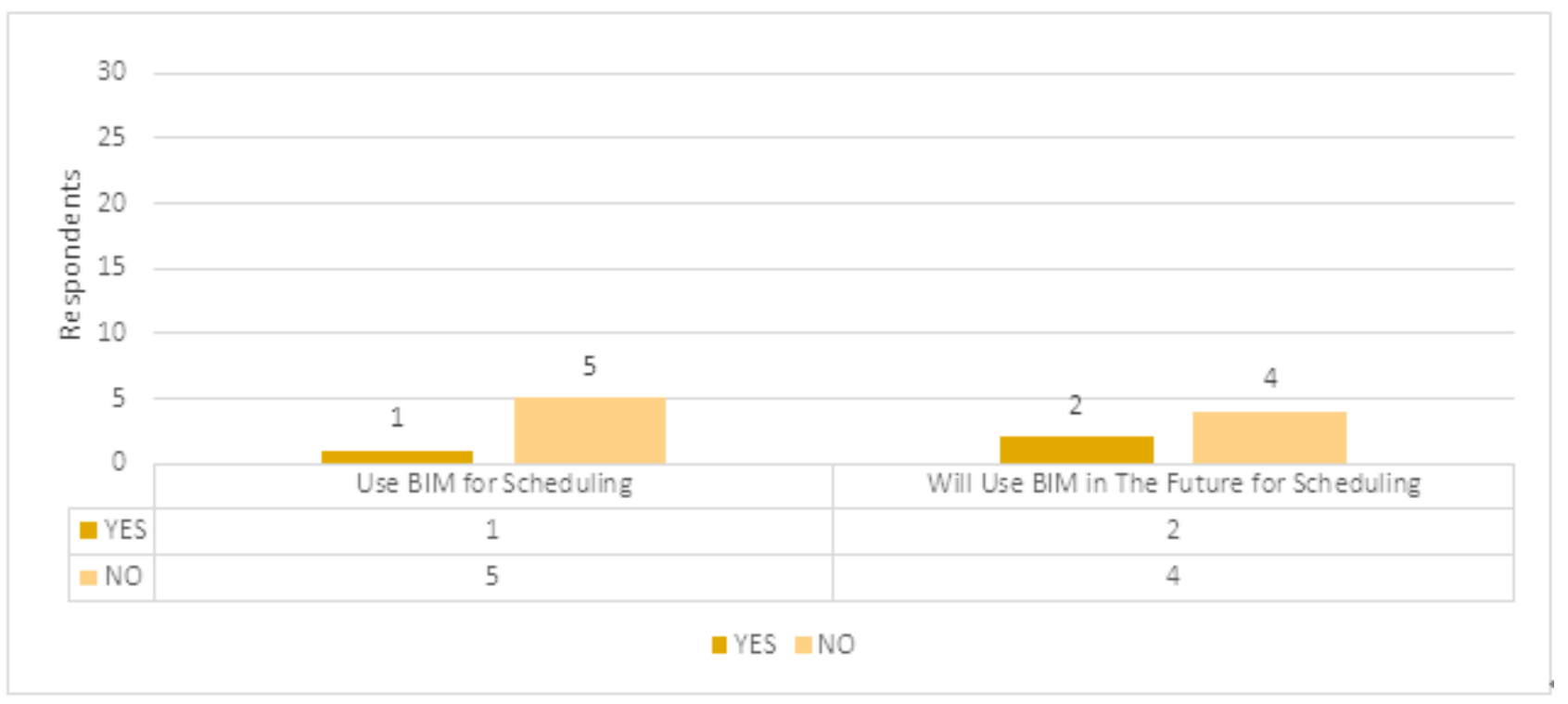

Chart 2. BIM Use for Estimating 


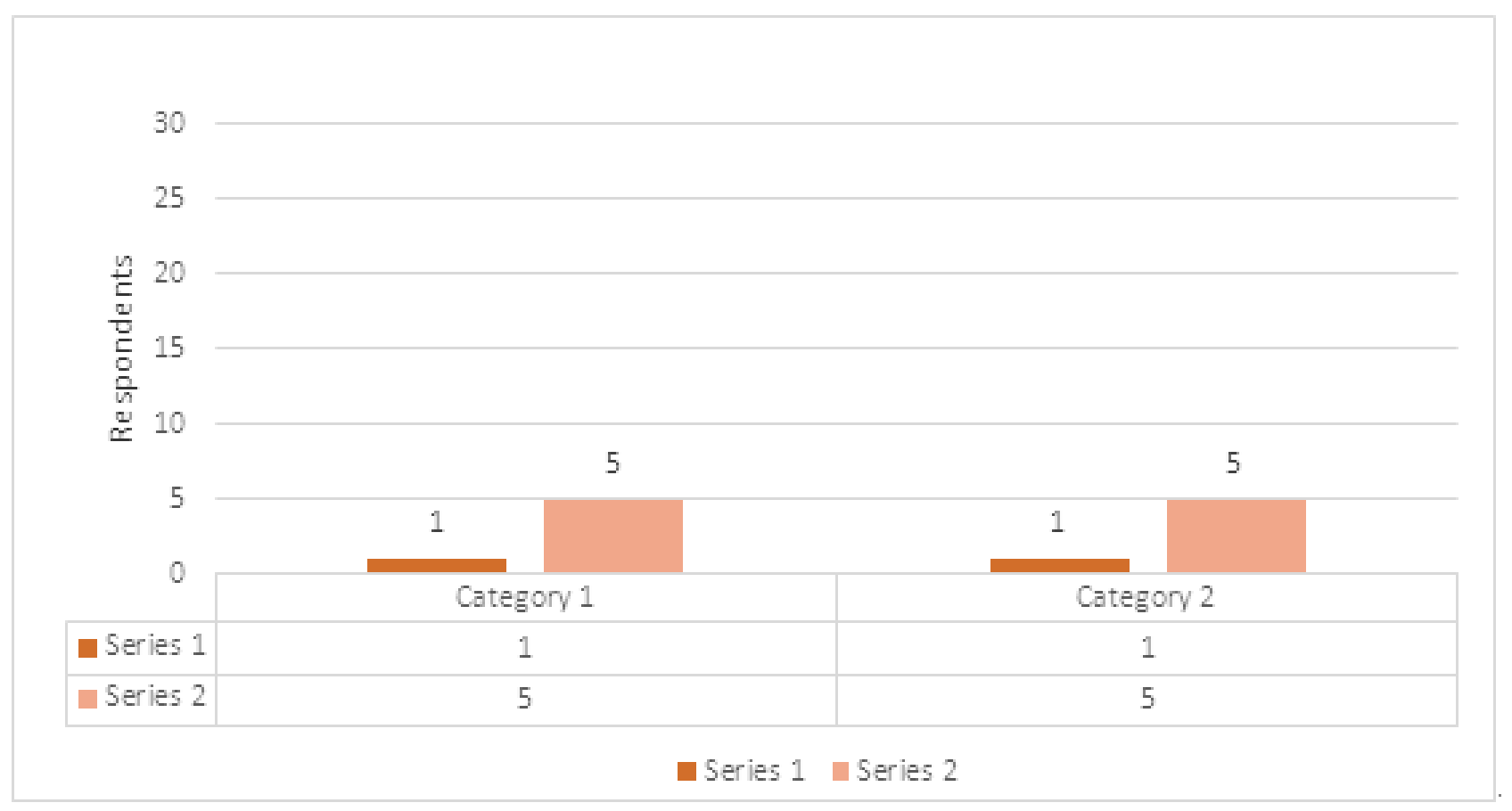

Chart 3. BIM Use for Scheduling

\section{Conclusions}

This research provides recommendations on the benefits of BIM for estimating multi-family projects by addressing the obstacles to embracing the concept of automated estimating, and scheduling. Major benefits from BIM implementation in all type of projects are: accurate and precise takeoff that subcontractors can rely on confidently early in the design phase, return on investment, reduction of change orders, reduction of requests for information, time saving, easier communication and collaboration between all stakeholders resulting in a successful project, thereby incentivizing subcontractors to challenge the following obstacles from the study, literature and personal investigation: Lack of experienced labor, time, and cost.

Interviewees pointed out the common use of BIM for collaboration and coordination in structural, mechanical, plumbing, and electrical trades, depending on the project size. Interviewees in addition pointed out the very limited use of it for estimating and scheduling, especially for small to mid-sized projects. Results driven from the respondents' answers to the survey questionnaire showed that subcontractors are still not prepared to shift the estimating from the conventional On Screen Takeoff to the automated estimating because they do not have the structure to adopt BIM especially if they have to build the model themselves, as it requires experienced labor, time and additional initial cost.

A comparison between the traditional estimating method and the automated estimating method (AEM) shows that greater accuracy can be obtained through AEM. However, the cost, time in developing the model, corporate structure and appropriate staff training can hamper the implementation of AEM among contractors.

\section{REFERENCES}

[1] Azhar, S. (2011). Building Information Modeling (BIM): Trends, Benefits, Risks, and Challenges for the AEC Industry. Leadership \& Management In Engineering, 11(3), 241-252. doi:10.1061/(ASCE)LM.1943-5630.0000127

[2] Choi, J., Kim, H., \& Kim, I. (2014). Open BIM-based quantity takeoff system for schematic estimation of building frame in early design stage. Retrieved from http://www.sciencedirect.com/science/article/pii/S22884300 14000037

[3] Giel, B. K., \& Issa, R. A. (2013). Return on Investment Analysis of Using Building Information Modeling in Construction. Journal Of Computing In Civil Engineering, 27(5), 511-521. doi:10.1061/(ASCE)CP.1943-5487.0000164

[4] Goldberg, H. E. (2007). Automated Estimating and Scheduling Using BIM. Cadalyst, 24(9), 45-48.

[5] http://www.nationalbimstandard.org/about.php

[6] Joyce, E. (2014). Show Me the Money: 5D-Cost Estimating Tools Paying Off. ENR: Engineering News-Record, 273(6), 44.

[7] Kraus, W. E., Watt, S., \& Larson, P. D. (2007). Challenges in Estimating Costs Using Building Information Modeling. AACE International Transactions, 01.1-01.3.

[8] Lu, W., Fung, A., Peng, Y., Liang, C., \& Rowlinson, S. (2014). Cost-benefit analysis of Building Information Modeling implementation in building projects through demystification of time-effort distribution curves. Building \& 
Environment,82317-327.

doi:10.1016/j.buildenv.2014.08.030

[9] McCuen, T. L. (2008). Scheduling, Estimating, and BIM: a Profitable Combination. AACE International Transactions, $1-8$.

[10] McCuen, T. L. (2009). The Quantification Process and Standards for BIM. AACE International Transactions, BIM.01.1-BIM.01.11.

[11] Nassar, K. (2012). Assessing Building Information Modeling Estimating Techniques Using Data from the Classroom. Journal Of Professional Issues In Engineering Education \& Practice, 138(3), 171-180.

doi:10.1061/(ASCE)EI.1943-5541.0000101

[12] Sattineni, A., \& Bradford II, R. (n.d.). ESTIMATING WITH BIM: A SURVEY OF US CONSTRUCTION COMPANIES. Retrieved from http://www.irbnet.de/daten/iconda/CIB_DC23693.pdf
[13] Sattineni, A. (2011). Building Information Modeling: Trends in the US Construction Industry. Design Principles \& Practice: An International Journal, 5(4), 187.

[14] Smith, P. (2014). BIM \& the 5D Project Cost Manager. Procedia - Social And Behavioral Sciences, 119(Selected papers from the 27th IPMA (International Project Management Association), World Congress, Dubrovnik, Croatia, 2013), 475-484. doi:10.1016/j.sbspro.2014.03.053

[15] Stanley, R., \& Thurnell, D. (2014). The benefits of, and barriers to, implementation of 5D BIM for quantity surveying in New Zealand. Australasian Journal Of Construction Economics And Building, The, 14(1), 105.

[16] STRUCSOFT SHIPS PROFESSIONAL METAL \& WOOD FRAMING FOR REVIT. (Cover story). (2010). CAD/CAM Update, 22(3), 1-2.

[17] Thurairajah, N., \& Goucher, D. (2013). Advantages and Challenges of Using BIM: A Cost Consultant's Perspective. 